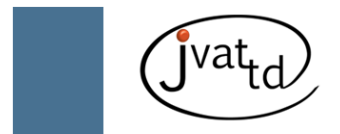

\title{
A novel lipocalin homologue from the venom gland of Deinagkistrodon acutus similar to mammalian lipocalins
}

Wei CB (1, 2), Chen J (3)

(1) Department of Chemistry and Biology, Western Anhui University, Lu'an, Anhui Province, People's Republic of China; (2) Lu'an Bionic Sensor and Testing Technique Laboratory of Anhui Province, Lu'an, Anhui Province, People's Republic of China; (3) Faculty of Life Science and Biotechnology, Ningbo University, Ningbo, Zhejiang Province, People's Republic of China.

\begin{abstract}
Lipocalins are involved in a variety of functions including retinol transport, cryptic coloration, olfaction, pheromone transport, prostaglandin synthesis, regulation of the immune response and cell homeostatic mediation. A full-length cDNA clone (named d-lipo), isolated from the venom gland cDNA library of Deinagkistrodon acutus, contained an insert of $664 \mathrm{bp}$ including an open reading frame that encodes a lipocalin homologue of 177 amino acids. Comparison of d-lipo and other related proteins revealed an overall amino acid identity of less than $21.5 \%$. Primary structures of d-lipo carried three structurally conserved regions (SCR) showing homologies to those of lipocalins. The first conserved Cys residue - the essential amino acid residue for the catalytic activity and unique to lipocalin-type prostaglandin D synthase (L-PGDS) in the lipocalin protein family - was identified in d-lipo at amino acid position 58. Phylogenetic tree analysis showed that d-lipo was in-between the large L-PGDS cluster and the small von Ebner's-gland proteins (VEGP) cluster. Moreover, d-lipo gene presented a high-level expression in the venom gland and a low-level expression in the brain and its expression was significantly increased under pathological conditions, suggesting a possible relationship between d-lipo mRNA expression and the venom gland inflammatory disease. This is also the first report of a lipocalin homologous gene identified in the venom gland of a snake.
\end{abstract}

Key words: Deinagkistrodon acutus, cDNA library, lipocalin, phylogeny, gene expression pattern analysis.

\section{INTRODUCTION}

The lipocalin protein family, one of the most remarkable protein families, is extremely widespread among bacteria, insects and mammals and exhibits extraordinary diversity at the level of sequence and function (1). A typical lipocalin consists of a 160-180 amino acid peptide folded into 8-9 $\beta$-strands that form a coffee filterlike cone with a hydrophobic interior. Lipocalin members share low levels of overall sequence conservation (approximately 20\%), but all share tertiary structure similarity containing three structurally conserved regions (SCRs) $(2,3)$. Based on the conservation of SCRs, the members were divided into two types. A core set of quite closely related proteins with three conserved SCRs were named kernel lipocalins, whereas a smaller number of more divergent sequences with no more than two of these three SCRs were named outlier lipocalins. The first of the SCRs is shared by all lipocalins and can be used as a diagnostic of family membership. It has been observed that lipocalins were involved in a variety of functions including retinol transport, cryptic coloration, olfaction, pheromone transport, prostaglandin synthesis, regulation of the immune response and cell homeostatic mediation (3).

Lipocalin-type prostaglandin D synthase (L-PGDS) is a bifunctional protein that possesses 
both the ability to synthesize PGD2 and to serve as a carrier protein for lipophilic molecules; moreover, it is the only enzyme among members of the lipocalin protein family. It has been well characterized in mammals as a kernel lipocalin and three conserved Cys residues in its primary structures were identified (4). In a recent study, a non-mammalian L-PGDS homologue without the catalytic $\mathrm{Cys}_{65}$ residue from zebrafish (Danio rerio) was characterized as a carrier protein for lipophilic ligands, but not as an enzyme (5). L-PGDS mRNAs are dominantly expressed in the central nervous system, heart and male genital organ (6-8). Von Ebner's gland protein (VEGP, also known as tear lipocalin) is possibly involved in taste transduction, in scavenging fatty acids and phospholipids from the corneal surface and stabilizing the tear film surface interface (9-12). The binding of siderophores and the prevention of bacterial growth may confer antimicrobial properties to VEGP (13). This protein is abundantly produced by human lachrymal glands, lingual von Ebner's glands and human prostate $(9,14,15)$.

Hundred-pace snake (Deinagkistrodon acutus) is endemic to southern China (16). In recent years, snake breeding was developed for commercial purposes (17). Due to frequent venom collection, inflammatory diseases in snake venom glands often occur and the pathogens are usually identified as bacteria. Although purification and gene expression of snake venom components have been extensively studied, there is no report on lipocalin homologue in snake venom glands (18-21). Herein, the molecular cloning of a fulllength cDNA encoding a lipocalin homologue (d-lipo) in Deinagkistrodon acutus venom gland is reported, as well as the phylogenetic relationships among d-lipo and known homologues from other species. The mRNA expression patterns of d-lipo gene in various tissues from healthy snakes and others with inflamed venom gland (IVG) were determined.

\section{MATERIALS AND METHODS}

\section{Materials}

Healthy and IVG Deinagkistrodon acutus were purchased from Yiwu Snake Research Institute, Yiwu city, Zhejiang province, China. All the primers were custom synthesized by Shanghai Sangon Biological Engineering Technology \&
Services Co., Ltd (Shanghai, China). RNAiso reagents, Oligotex-dT30, RNA PCR kit (AMV) ver. 3.0 and cDNA library construction kit were purchased from TaKaRa Ltd. (Kyoto, Japan). Other chemicals were of analytical reagent.

\section{RNA Isolation and CDNA Library Construction}

Total RNA was extracted from the venom gland of a healthy Deinagkistrodon acutus using RNAiso reagents. mRNA was obtained using Oligotex-dT30 and TaKaRa cDNA library construction kit according to the manufacturer's protocols as previously reported (22).

\section{Obtaining the cDNA Clones Encoding the Lipocalin Homologue}

A random set of 283 clones were partially sequenced by the ABI Prism $3773 \mathrm{DNA}^{\oplus}$ sequence (Applied Biosystems, USA) and BLASTP search (http://blast.ncbi.nlm.nih.gov/Blast.cgi) was used to identify the lipocalin homologue. The positive clones were subsequently amplified using T7 and T3 primers of the pA3neo vector. The longest insertion was then auto-sequenced in both directions to obtain the complete cDNA sequence.

\section{Construction of Phylogenetic Tree and Sequence Analysis on Lipocalin Gene}

The cleavage site of signal peptides was predicted by SignalP 3.0 software program (http://www.cbs.dtu.dk/services/SignalP/) (23). A multiple alignment was performed by using the ClustalW program (Amplicon Ltd.) (24) and displayed by BioEdit Sequence Alignment Editor (Tom Biosciences Ltd.) (25). A phylogenetic tree was constructed using the reference amino acid sequences of animal lipocalins by the neighborjoining method and displayed by TreeView software (Michael Eisen Software Ltd.). Accession numbers of used sequences are: hundred-pace snake, AM889305; platypus (Ornithorhynchus anatinus),XM_001515029; chicken(Gallus gallus) L-PGDS, NM_204259; spotted green pufferfish (Tetraodon nigroviridis), CAAE01014601; tropical clawed frog (Xenopus tropicalis), BC118854; African clawed frog (Xenopus laevis), X84414; giant toad (Bufo marinus), X67952; horse (Equns caballus), XM_001498160, and human (Homo sapiens) VEGP, X62418, and human L-PGDS, M61901; mouse (Mus musculus) L-PGDS, X89222; rat (Rattus norvegicus) VEGP, X52016, 
and rat L-PGDS, NM_013015; zebrafish (Danio rerio) L-PGDS, NM_213634.

\section{d-lipo Gene Expression Pattern Analysis}

Fifty nanogram of total RNA from the venom gland, brain, heart, kidney, liver, intestine and spleen of healthy and IVG snakes was purified using RNAiso regents. RT-PCR was done using the RNA PCR Kit (AMV) Ver.3.0 with primers d-lipo(+): 5'- TCATGGATATGTTCACGCCAC -3 ' and d-lipo(-): 5' - ATATATCTTCTGTGGGGAGG -3'. As an internal PCR control, a pair of degenerate primers actindF(+): 5'-ACXAAYTGGGAYGAYA TGGARAA-3' and actindR(-): 5'- GCRTAXCC YTCRTAXATXGGXAC - $3^{\prime}(\mathrm{R}=\mathrm{A}$ and $\mathrm{G} ; \mathrm{Y}=\mathrm{T}$ and $C ; X=A, T, C$ and $G$ ) were designed and used to amplify a fragment of housekeeping $\beta$-actin gene. PCR was done in a Mastercycler thermal cycler (Eppendorf Ltd., Germany): one cycle of four minutes at $94^{\circ} \mathrm{C} ; 30$ cycles of 40 seconds at $94^{\circ} \mathrm{C}, 30$ seconds at $60^{\circ} \mathrm{C}$, and one minute at $72^{\circ} \mathrm{C}$; and a final extension at $72^{\circ} \mathrm{C}$ for ten minutes. Successful amplification of fragments of the expected size was confirmed by electrophoresis through $1 \%(\mathrm{w} / \mathrm{v})$ agarose gels.

\section{RESULTS}

\section{Cloning and Sequence of the Snake Gland d-lipo mRNA}

After BLASTP search using partial sequences, 4 out of 283 clones showed low sequence similarity to some sequence encoding members of lipocalin family and shared $>99 \%$ nucleotide identity among themselves. The longest clone was completely sequenced. The full-length cDNA clone was 664 base pair (bp) in size, containing an open reading frame of $531 \mathrm{bp}$. The predicted d-lipo had 177 amino acid residue $(19.8 \mathrm{kDa})$ was comparable in size to that of the lipocalin homologues from other species. The d-lipo cDNA clone has an ATG initiating codon at nucleotide 31-33, followed by a hydrophobic sequence, characteristic of a typical signal peptide sequence. The predicted cleavage site was most likely between amino acids 18 and 19 (VQA/NE). This suggests that d-lipo could be secreted in the mature form after cleavage. The 3'UTR of d-lipo cDNA was $100 \mathrm{bp}$ long.

\section{Sequence Analysis}

D-lipo was most similar to a sequence (XM_001515029) from platypus with 21.5\% amino acid identity. It had $20.9 \%$ amino acid identity to a human VEGP and $18.0 \%$ to a chicken L-PGDS. The deduced amino acid sequence of d-lipo was aligned with the related sequences from other organisms (Figure 1). Previous work has analyzed the conservation of sequence and structure in the lipocalin protein family (3). The common core characteristic of the lipocalin fold is dominated by three large structurally conserved regions (SCRs): SCR1, SCR2 and SCR3. d-lipo also had similar three regions (Figure 1) although the sequence was more variable, suggesting it was a distant member of the lipocalin protein family.

It was reported that mammalian L-PGDS contain three conserved Cys residues in their primary structures. The first Cys residue at amino acid position 65 in rat and mouse L-PGDS was identified as the essential amino acid residue for the catalytic activity, being conserved in all mammalian L-PGDS and unique to L-PGDS in the lipocalin protein family as it has never been found in other lipocalins $(3,26,27)$. The d-lipo contained a Cys residue at amino acid position 58, corresponding to the essential amino acid residue for prostaglandin D synthase (PGDS) activity in mammals. However, sequences of platypus, human VEGP, rat VEGP, horse, spotted green pufferfish and zebrafish L-PDGS homologue, had no corresponding Cys residue (Figure 1). The other two Cys residues (Cys89 and Cys186 in the rat L-PGDS) are essential for disulfide bond formation, and these residues were conserved in all L-PGDS, rat and human VEGP, and in platypus lipocalin homologue, except in horse (Figure 1).

Phylogenetic tree analysis on amino acid sequences of the d-lipo homologues was carried out. Some significant clusters were identified. Sequences from African clawed frog, tropical clawed frog and giant toad were tightly grouped and formed a small cluster with L-PGDS of chicken. L-PGDS of zebrafish and a sequence from spotted green pufferfish formed another small cluster. L-PGDS of mouse, rat and human grouped tightly and formed the third small cluster. These three small clusters formed a large "L-PGDS" cluster which was similar to that previously reported, and the phylogenetic relationships between those proteins coincided well with the evolutionary relationships of their organisms (5). VEGP of rat, human and a sequence from horse formed a small "VEGP" cluster, whereas d-lipo of hundred-pace snakes 


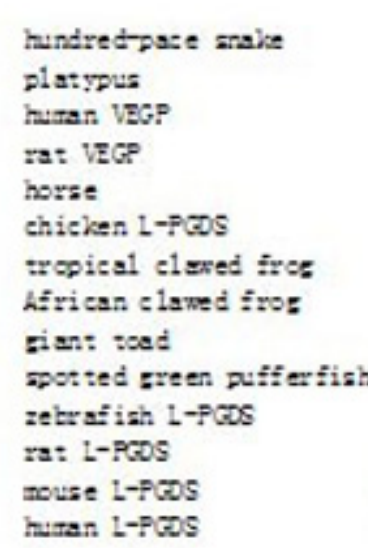

hindredpoce araike

platypus

ra: VER

horse

chicken L-PCDS

tropiesl elaxed fres

gians roed

apotsed green puffertish

ra: L-PGOS

hiran L-PGS

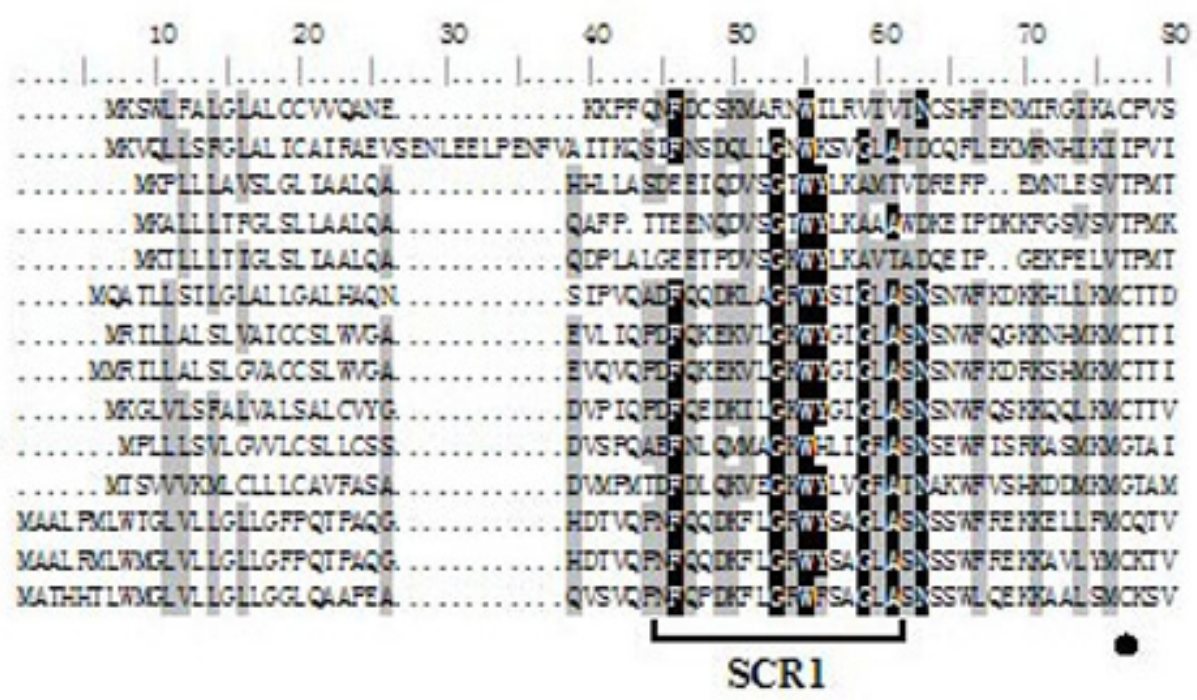

90

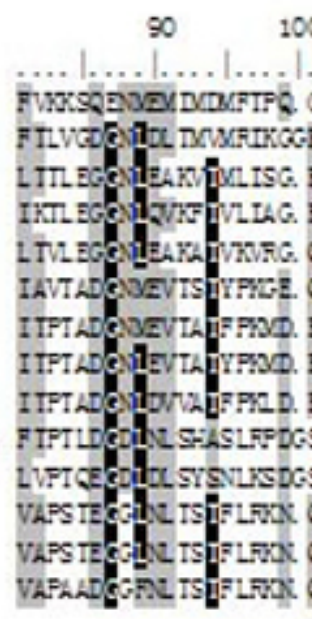

\section{$00 \quad 110 \quad 120$}

120

130

160

150

160

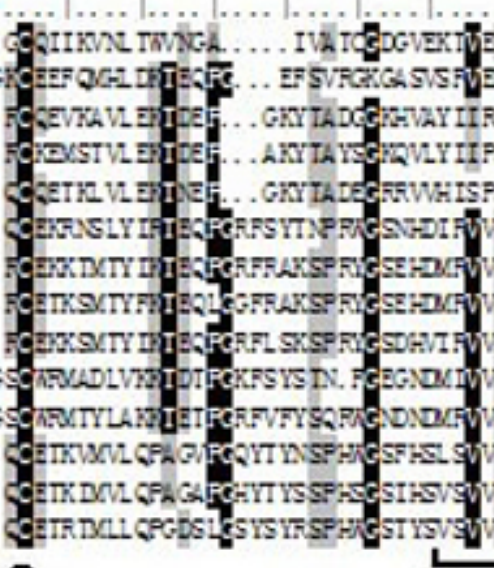

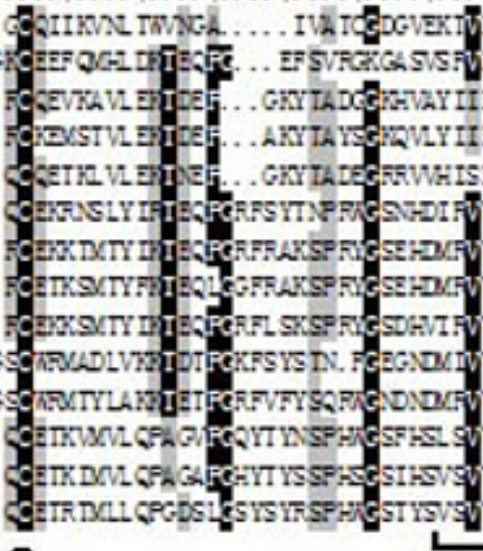

SCR2 hundredose maks

platyous

human VEGP

fas: $1 E G$

\section{horse}

chicken 1-PCOS

tropical clared fros

hfrican clawed frog

gian: sead

sported green puffertish

zebrafiah L-PCDS

ra: $1-P C D S$

mouse L-PCDS

himan L-PGos hundredpase rabe

pla:yous

huran VEGP

Fa: $V E$

horse

chicken L-PCDS

tropical elswed freg

herican clawed zrog

gisn: sced

apotsed green pufferfish

zebrafiah L-PCDS

ra: $1-P C D S$

mouse I-PCDS

huran I-PCDS 


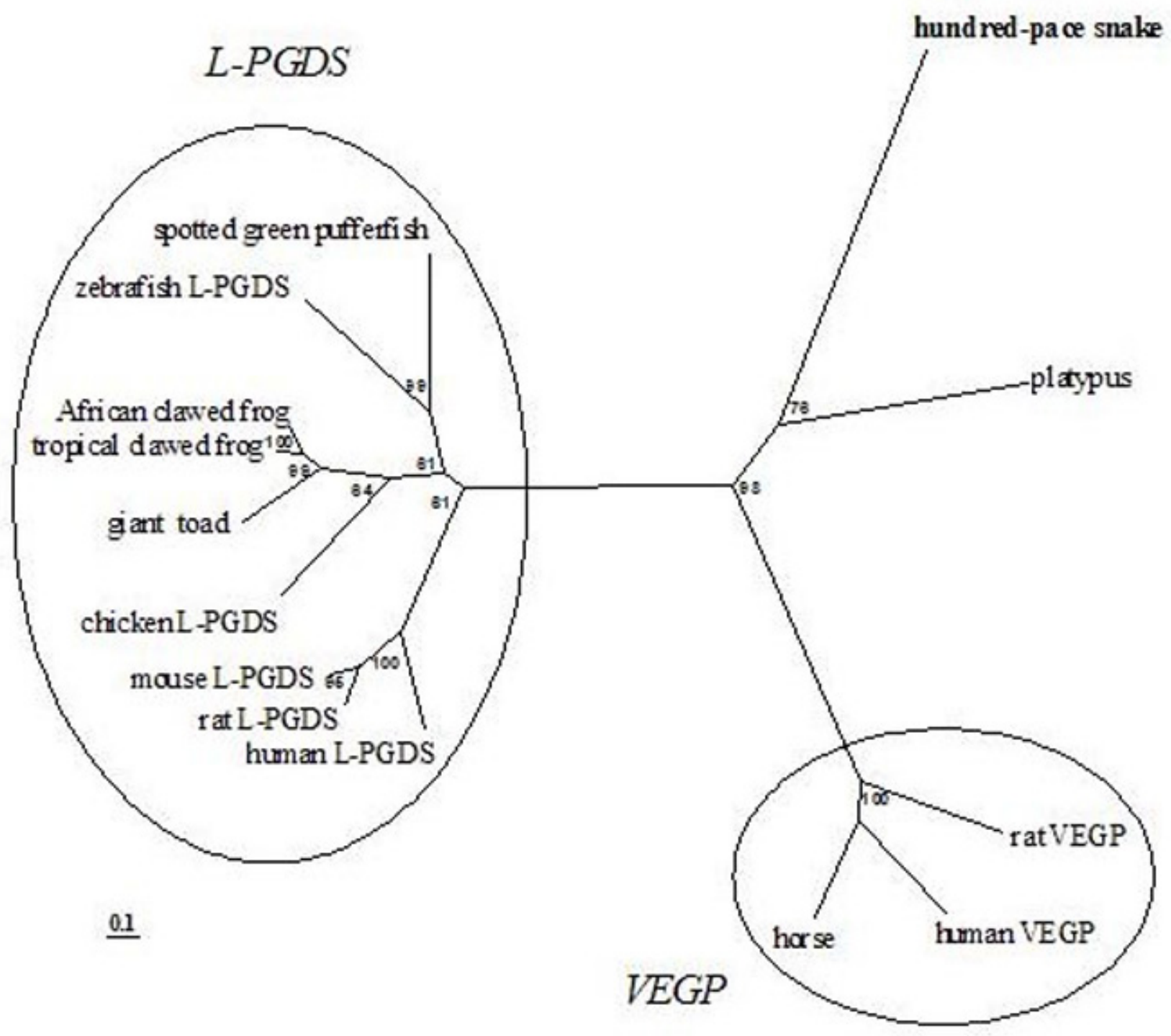

Figure 2. Phylogenetic tree analysis on amino acid sequences of some homologues related to d-lipo using ClustalW program. The values at the forks indicate the percentage of trees in which this grouping occurred after bootstrapping the data with 1000 replicates (shown only when $>60 \%$ ). The scale bar shows the number of substitutions per base.

grouped with a sequence of platypus, both were between the "L-PGDS" cluster and the "VEGP" cluster (Figure 2).

\section{d-lipo Gene Expression Pattern}

In order to examine d-lipo gene expression pattern in different tissues, RT-PCR analysis was performed using total RNA from the venom gland, liver, spleen, kidney, brain, heart and intestine of hundred-pace snakes. A $300 \mathrm{bp}$ fragment (the expected size) of d-lipo gene was amplified from the samples of the venom gland and brain, while nothing could be amplified from the other tested tissues (Figure 3). The mRNA expression of d-lipo gene from venom gland samples of IVG snakes was significantly increased when compared to that of healthy snakes. In addition, little changes were observed in brain samples and nothing in other tested tissues (Figure 3). A $281 \mathrm{bp}$ fragment (the expected size) of $\beta$-actin gene was successfully amplified from all tissue tested. Ratio of optic density (ROD) of d-lipo to $\beta$-actin was 1.17 in the venom gland of healthy snakes, while 17.22 in that of IVG snakes. ROD of d-lipo to $\beta$-actin in the brain of healthy and IVG snakes were 0.31 and 0.33 , respectively. Therefore, d-lipo mRNA in the venom gland of hundred-pace snakes was increased by up to 15 fold under inflammatory condition. 


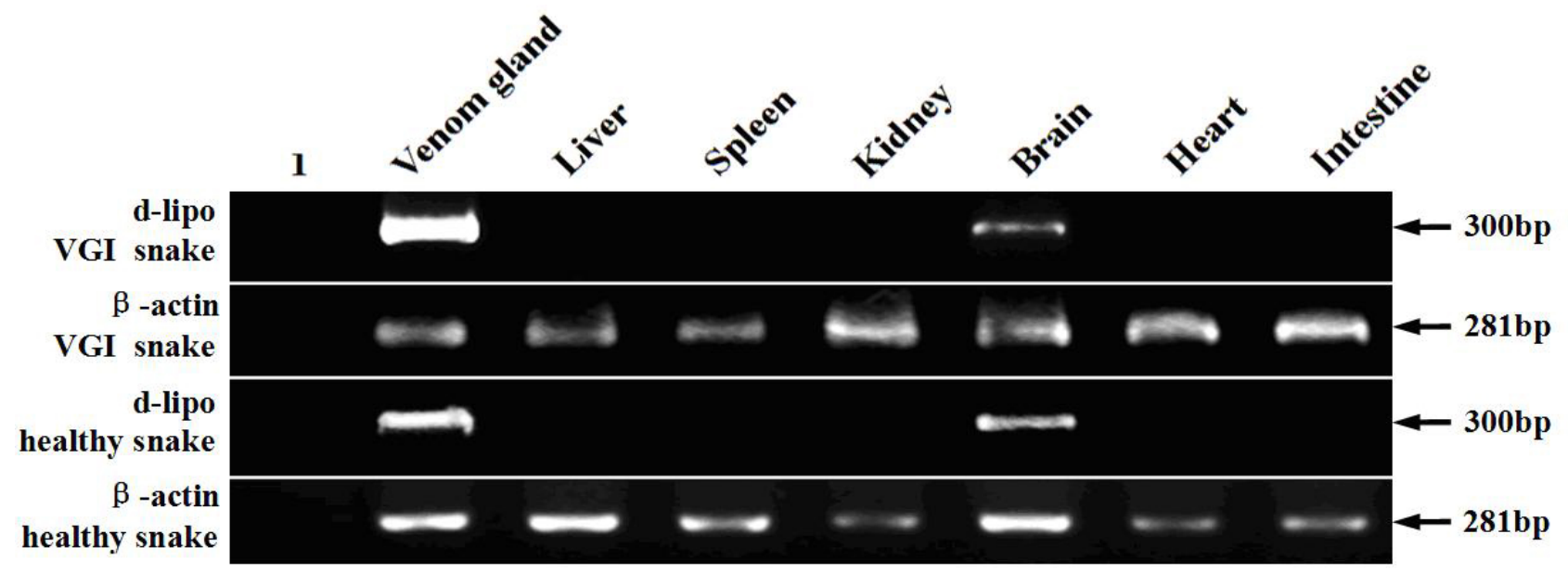

Figure 3. RT-PCR analysis of d-lipo mRNA expression in various tissues of healthy and IVG hundred-pace snakes. (1) A control reaction without RNA template. $\beta$-actin amplification was included as internal control. The size of the products is shown on the right.

\section{DISCUSSION}

In the present study, a full-length cDNA clone encoding a lipocalin homologue (d-lipo) from hundred-pace snake venom gland was sequenced. The predicted d-lipo is 177 amino acids long with a signal sequence of 18 amino acids in its N-terminus. It is the first report of a gene encoding a lipocalin homologue in the venom gland of a snake.

Lipocalin family proteins show conserved folding patterns and carry three structurally conserved regions (SCRs), which are thought to play an important role in receptor binding $(2,28)$. Primary structures of d-lipo carried SCRs showing homologies to those of lipocalins (Figure 1). The result indicates that d-lipo is to be considered a member of the lipocalin protein family. Moreover, d-lipo is similar to a sequence of platypus with $21.5 \%$ amino acid identity.

Multiple alignments showed that d-lipo contained the conserved first Cys residues which are essential for the catalytic activity of mammalian L-PGDSs and unique to L-PGDS in the lipocalin protein family, which suggests a relationship between d-lipo and L-PGDS (4). Expression profiles of hundred-pace snakes were different from other known lipocalins. The present results showed that d-lipo gene presented a high-level expression in the venom gland and a low-level expression in the brain, which does not agree with previous studies that demonstrated high-level expression of animal L-PGDS genes in the brain and heart $(4,5)$. Mammalian VEGP is highly expressed in the human lachrymal gland, von Ebner's gland and prostate $(9,14,15)$.

It is known that snake venom gland has evolved from salivary glands, therefore d-lipo was likely to be originally related to VEGP. The tissue expression profiles suggested that d-lipo was related to both mammalian L-PGDS and VEGP in some measure. Phylogenetic tree analysis showed some evidences for the classification of d-lipo. Since all known L-PGDS homologues of fish, bird, amphibian and mammals fall into the "L-PGDS" cluster, homologues of reptiles would be most likely to be placed in this cluster, if it existed. However, d-lipo was in-between, it did not fall into either the large "L-PGDS" cluster or the small "VEGP" cluster, indicating that it is possibly a atypical L-PGDS. The origin and evolutionary relationship of d-lipo, L-PGDS and VEGP would be an interesting matter to be further studied.

Multiple alignments showed that d-lipo contain three conserved Cys residues that correspond to those of mammalian L-PGDS, indicating a possible catalytic activity on producing PGD2, which was involved in numerous physiological and pathological events. Mammalian VEGP is possibly involved in taste transduction (9, 10). Since the snake venom gland is extremely specialized for producing venom, d-lipo was not likely to have a role in taste transduction. The intracellular protection of enzymes and membranes against the detergent effects of fatty 
acids has been postulated as a role for intestinal fatty acid binding proteins; therefore, d-lipo may have the intracellular protection of enzymes and membranes against the surface-active properties of free fatty acids and other molecules that are generated in the venom gland itself (29).

Some lipocalins, such as a1-acid-glycoprotein and neutrophil gelatinase-associated lipocalin (NGAL), have been implicated at one stage or another of pathophysiological events such as acute systemic inflammation (30). Recently, complexes of matrix metalloproteinase-9 (MMP9) with NGAL were found in the urine obtained from breast cancer patients and the data suggested a possible role for NGAL in the protection of MMP-9 against autolysis (31). It was known that snake venom metalloproteinases are relevant in the pathophysiology of envenomation, being responsible for local and systemic hemorrhage frequently observed in the victims (32). Nevertheless, whether d-lipo posses a role in the protection of venom metalloproteinases remains unknown. The binding of microbial siderophores confers antimicrobial activity to VEGP, a1-microglobulin, and NGAL (13, 33, 34). Our study on IVG snakes showed that d-lipo mRNA in venom glands of hundred-pace snakes was significantly increased under pathological conditions, suggesting a possible relationship between d-lipo mRNA expression and the venom gland inflammatory disease.

The cDNA sequence of the lipocalin gene in the venom gland of hundred-pace snakes reported herein was deposited in the EMBL/GenBank/ DDBJ database (accession number AM889305).

\section{ACKNOWLEDGEMENTS}

We thank Dr. Zheng HY, Zhejiang Academy of Agricultural Sciences, Hangzhou, China, for help in cDNA library construction.

\section{COPYRIGHT}

(c) CEVAP 2012

\section{SUBMISSION STATUS}

Received: April 5, 2011.

Accepted: August 10, 2011.

Abstract published online: August 16, 2011.

Full paper published online: February 28, 2012.

\section{CONFLICTS OF INTEREST}

The authors declare no conflicts of interest.

\section{FINANCIAL SOURCE}

Natural Scientific Foundation of Anhui Province Education Commission (KJ2010A328) provided the financial grants.

\section{ETHICS COMMITTEE APPROVAL}

The present study was approved by the Ethics Committee of Western Anhui University, China.

\section{CORRESPONDENCE TO}

Chuanbao Wei, Department of Chemistry and Biology, Western Anhui University, Lu'an City 237012, Anhui Province, People's Republic of China. Phone: +86 564 3305073. Fax: +86 564 3305033. Email: weichuanbao@sina.com or hsxz@wxc.edu.cn

\section{REFERENCES}

1. Pugalenthi G, Kandaswamy KK, Suganthan PN, Archunan G, Sowdhamini R. Identification of functionally diverse lipocalin proteins from sequence information using support vector machine. Amino Acids. 2010;39(3):777-83.

2. Flower DR, North ACT, Attwood TK. Structure and sequence relationships in the lipocalins and related proteins. Protein Sci. 1993;2(5):753-61.

3. Flower DR. The lipocalin protein family: structure and function. Biochem J. 1996;318(Pt 1):1-14.

4. Urade Y, Hayaishi O. Prostaglandin D synthase: structure and function. Vitam Horm. 2000;58:89-120.

5. Fujimori K, Inui T, Uodome N, Kadoyama K, Aritake $\mathrm{K}$, Urade Y. Zebrafish and chicken lipocalin-type prostaglandin D synthase homologues: conservation of mammalian gene structure and binding ability for lipophilic molecules, and difference in expression profile and enzyme activity. Gene. 2006;375:14-25.

6. Urade Y, Kitahama K, Ohishi H, Kaneko T, Mizuno $\mathrm{N}$, Hayaishi O. Dominant expression of mRNA for prostaglandin D synthase in leptomeninges, choroid plexus, and oligodendrocytes of the adult rat brain. Proc Natl Acad Sci USA. 1993;90(19):9070-4.

7. Eguchi Y, Eguchi N, Oda H, Seiki K, Kijima Y, Matsuura $\mathrm{Y}$, et al. Expression of lipocalin-type prostaglandin D synthase (beta-trace) in human heart and its accumulation in the coronary circulation of angina patients. Proc Natl Acad Sci USA. 1997;94(26):1468994.

8. Tokugawa Y, Kunishige I, Kubota Y, Shimoya $K$, Nobunaga T, Kimura $T$, et al. Lipocalintype prostaglandin $\mathrm{D}$ synthase in human male reproductive organs and seminal plasma. Biol Reprod. 1998;58(2):600-7.

9. Bläker M, Kock K, Ahlers C, Buck F, Schmale H. Molecular cloning of human von Ebner's gland protein, a member of the lipocalin superfamily highly expressed in lingual salivar glands. Biochim Biophys Acta. 1993;1172(1-2):131-7. 
10. Schmale $\mathrm{H}$, Holtgreve-Grez $\mathrm{H}$, Christiansen $\mathrm{H}$. Possible role for salivary gland protein in taste reception indicated by homology to lipophilic carrier proteins. Nature. 1990;343(6256):366-9.

11. Gasymov OK, Abduragimov AR, Prasher P, Yusifov TN, Glasgow BJ. Tear lipocalin: evidence for a scavenging function to remove lipids from the human corneal surface. Invest Ophthalmol Vis Sci. 2005;46(10):3589-96.

12. Nagyova B, Tiffany JM. Components responsible for the surface tension of human tears. Curr Eye Res. 1999;19(1):4-11.

13. Fluckinger M, Haas H, Merschak P, Glasgow BJ, Redl B. Human tear lipocalin exhibits antimicrobial activity by scavenging microbial siderophores. Antimicrob Agents Chemother. 2004;48(9):3367-72.

14. Redl B, Holzfeind P, Lottspeich F. cDNA cloning and sequencing reveals human tear prealbumin to be a member of the lipophilic-ligand carrier protein superfamily. J Biol Chem. 1992;267(28):20282-7.

15. Holzfeind P, Merschak P, Rogatsch H, Culig Z, Feichtinger H, Klocker H, Redl B. Expression of the gene for tear lipocalin/von Ebner's gland protein in human prostate. FEBS letters.1996;395(2-3):95-8.

16. Wei CB, Chen J, Li JH. Acutolysin C, a weak hemorrhagic toxin from the venom of Agkistrodon acutus with leucoagglutination activity. J Venom Anim Toxins incl Trop Dis. 2011;17(1):34-41.

17. Guy N, Xavier B. Body condition threshold for breeding in a viviparous snake. Oecologia.1996;107(3):301-6.

18. Queiroz MR, Mamede CC, Fonseca KC, Canabrava LC, França LV, Silva MC, et al. Biological characterization of a myotoxin phosphoplipase $\mathrm{A}_{2}$ homologue purified from the venom of the snake Bothrops moojeni. J Venom Anim Toxins incl Trop Dis. 2011;17(1):49-58.

19. Ponlapat R, Chuanchom M, Lawan C, Jaradpong A, Tanin I. Molecular cloning of novel serine proteases and phospholipases $\mathrm{A}_{2}$ from green pit viper (Trimeresurus albolabris) venom gland cDNA library. Toxicon. 2006;47(3):279-87

20. Guarnieri MC, Melo ES, Melo KM, AlbuquerqueModesto JC, Prieto-da-Silva AR, et al. Cloning of a novel acidic phospholipase $\mathrm{A}_{2}$ from the venom gland of Crotalus durissus cascavella (Brazilian northeastern rattlesnake). J Venom Anim Toxins incl Trop Dis. 2009;15(4):745-61.

21. Mesquita-Ferrari RA, Moraes CK de, Micocci KC, Selistre-de-Araújo HS ALT-C, a disintegrin-like Cys-rich protein from Bothrops alternatus, increases skeletal myoblast viability. J Venom Anim Toxins incl Trop Dis. 2009;15(2):325-39.

22. $\mathrm{Hu} J \mathrm{R}, \mathrm{Cao} \mathrm{MF}$, Chen J. Characterization of the cDNA encoding a BPI/LBP homologue in venom gland of the hundred pace snake Deinagkistrodon acutus. Curr Zool. 2009; 55(5): 376-82.
23. Bendtsen JD, Nielsen H, von Heijne G, Brunak S. Improved prediction of signal peptides: SignalP 3.0. J Mol Biol. 2004;340(4):783-95.

24. Thompson JD, Higgins DG, Gibson TJ. CLUSTALW: improving the sensitivity of progressive multiple sequence alignment through sequence weighting, position-specific gap penalties and weight matrix choice. Nucleic Acids Res.1994;22(22):4673-80.

25. Hall TA. BioEdit: a user-friendly biological sequence alignment editor and analysis program for Windows 95/98/NT. Nucl Acids Symp Ser. 1999;41:95-8.

26. Urade Y, Tanaka T, Eguchi N, Kikuchi M, Kimura H, Toh $\mathrm{H}$, et al. Structural and functional significance of cysteine residues of glutathione-independent prostaglandin D synthase. Identification of Cys65 as an essential thiol. J Biol Chem. 1995;270(3):1422-8.

27. Shimamoto S, Yoshida T, Inui T, Gohda K, Kobayashi $\mathrm{Y}$, Fujimori K, et al. NMR solution structure of lipocalin-type prostaglandin D synthase: evidence for partial overlapping of catalytic pocket and retinoic acid-binding pocket within the central cavity. J Biol Chem. 2007;282(43):31373-9.

28. Ganfornina MD, Gutiérrez G, Bastiani M, Sánchez D. A phylogenetic analysis of the lipocalin protein family. Mol Biol Evol. 2000;17(1):114-26.

29. Sacchettini JC, Gordon JI, Banaszak LJ. Crystal structure of rat intestinal fatty-acid-binding protein. Refinement and analysis of the Escherichia coliderived protein with bound palmitate. J Mol Biol. 1989;208(2):327-39.

30. Bonventre JV. Diagnosis of acute kidney injury:from classic parameters to new biomarkers. Contrib Nephrol. 2007;156:213-9.

31. Kubben FJ, Sier CF, Hawinkels LJ, Tschesche H, van Duijn W, Zuidwijk K, et al. Clinical evidence for a protective role of lipocalin-2 against MMP-9 autodegradation and the impact for gastric cancer. Eur J Cancer. 2007;43(12):1869-76.

32. Teixeira $\mathrm{C}$ de F, Fernandes CM, Zuliani JP, Zamuner SF. Inflammatory effects of snake venom metalloproteinases. Mem Inst Oswaldo Cruz. 2005;100(Suppl 1):181-4.

33. Akerstrom B, Maghzal G, Winterbourn CC, Kettle AJ. The lipocalin alpha1-Microglobulin has radical scavenger activity. J Biol Chem. 2007;282(43):31493503.

34. Flo TH, Smith KD, Sato S, Rodriguez DJ, Holmes MA, Strong RK, et al. Lipocalin 2 mediates an innate immune response to bacterial infection by sequestrating iron. Nature. 2004;432(7019):917-21. 